\title{
Breaking the habit
}

\section{Commentary on: Policy responses to problematic video game use: A systematic review of current measures and future possibilities (Király et al., 2018)}

\author{
KAI WILHELM MÜLLER*
}

\begin{abstract}
Outpatient Clinic for Behavioral Addiction, Department of Psychosomatic Medicine and Psychotherapy, University Medical Center,
\end{abstract} Johannes Gutenberg University Mainz, Mainz, Germany

(Received: January 31, 2018; revised manuscript received: June 29, 2018; accepted: June 30, 2018)

\begin{abstract}
Internet gaming disorder has been widely recognized as a new health issue. At present, we are experiencing a rapid growth of knowledge on different aspects of this disorder, such as, for instance, prevalence rates, underlying neurobiological mechanisms, and treatment strategies. In contrast, preventing individuals from developing Internet gaming disorder is a matter that has not yet progressed sufficiently. Although we can basically refer to measures and techniques known to be effective in preventing other addictive behaviors, the special demands of preventing Internet gaming disorder remain largely obscured or disregarded. The policy actions identified in the review by Király et al. (2018) demonstrate that first preventive approaches have been initiated but, on the other hand, it also points out that empirical research on their feasibility and effectiveness needs improvement.
\end{abstract}

Keywords: harm reduction, Internet gaming disorder, policy, prevention

\section{GOOD REASONS FOR TAKING ACTION}

Numerous data of the past decade have demonstrated that playing computer games can run out of control. In the worst case, the phenomenon called Internet gaming disorder can lead to functional impairment and psychopathological symptoms including the development of further mental disorders. Research has made progress in several aspects during the rise of Internet gaming disorder. We know a lot about its epidemiological features, although it is well known that prevalence rates vary considerably, which is probably due to different methodological approaches (e.g., Ferguson, Coulson, \& Barnett, 2011). We have some deepened insights into neurobiological and neuropsychological features of Internet gaming disorder, indicating a disturbed reward processing in patients and an increased incentive sensitization (e.g., Kuss \& Griffiths, 2012). We even have at least some information on the appropriateness and feasibility of treatment strategies for this new disorder (e.g., King et al., 2017). Yet, what is desperately missing are solid concepts and data on how to prevent adolescents and adults from developing Internet gaming disorder. In that respect, the study by Király et al. (2018) provides a sound overview on existing strategies and simultaneously illustrates our current awfully limited knowledge on effective prevention strategies.

While from a broader perspective, that is, prevention is usually based on multiple strategies (e.g., school-based programs, educational approaches, etc.), the study by Király et al. (2018) specifically focuses on existing and potential governmental actions. This specific focus perfectly makes sense because of the complexity of the matter mentioned above. Availability, which we know from prevention of nicotine use and gambling participation, plays a crucial role here.

\section{A FIRST IDEA: LIMITING AVAILABILITY}

As depicted above, availability has to be recognized as one major factor in preventing certain dysfunctional behaviors (e.g., nicotine use, alcohol consumption, and gambling participation). Undoubtedly, restricting availability does not provide a full solution for this problem, but one can consider it as one piece of a jigsaw. Derived from the literature, Király et al. (2018) list three major measures to limit availability (shutdown, selective shutdown, and fatigue) and one more specific approach enabling greater parental control.

Disabling the access to online computer games for a certain time appears to be a promising approach. Clinical experience shows that individuals who are about to develop problematic gaming habits tend to extend gaming into the late hours. Actually, a high percentage of patients in

\footnotetext{
* Corresponding address: Kai Wilhelm Müller; Outpatient Clinic for Behavioral Addiction, Department of Psychosomatic Medicine and Psychotherapy, University Medical Center, Johannes Gutenberg University Mainz, Untere Zahlbacher Straße 8, Mainz 55131, Germany; Phone: +49 6131 174287; Fax: +49 6131 176439; E-mail: muellka@uni-mainz.de
}

This is an open-access article distributed under the terms of the Creative Commons Attribution-NonCommercial 4.0 International License, which permits unrestricted use, distribution, and reproduction in any medium for non-commercial purposes, provided the original author and source are credited, a link to the CC License is provided, and changes - if any - are indicated. 
treatment display a disrupted circadian rhythm and related consequences, such as exhaustion, attention problems, and day sleepiness (Müller, Beutel, \& Wölfling, 2014). These data are confirmed by population-based surveys (Cheung \& Wong, 2011; Griffiths, Davies, \& Chappell, 2004). Thus, from a theoretical framework, those consequences contribute to a proceeding loss of psychosocial functioning that may act as a maintaining factor for Internet gaming disorder in the long run. More generally, preliminary data have demonstrated that also among adolescents not affected by Internet gaming disorder, nightly gaming is associated with poorer well-being and higher depression scores (Lemola et al., 2011). Thus, it makes sense taking measures to protect the sleep of adolescents by defining a nightly time-out for online computer games.

Nevertheless, the data found by Király et al. (2018) are to some extent disappointing. Although gaming after midnight decreased among adolescents, the average time spent playing games did not change significantly. Yet, the paucity of empirical data available demonstrates the urgent necessity to show greater enthusiasm in evaluating such programs. Strategies that are logically derived from existing theory and strategies that can be implemented ecologically are promising candidates for research. Of course, this is a point where governmental action becomes relevant in a second way. Empirically sound evaluations of prevention programs demand financial capacities. In order to avoid conflicts of interests and to secure good scientific practice, governmental grants are required to support empirical research here.

\section{RETHINKING PREVENTION: HARM REDUCTION}

The concept of harm reduction aims at reducing the negative repercussions arising from a problematic behavior rather than prohibiting or reducing the behavior itself. It can be therefore considered as a sophisticated approach especially with regard to the special demands of computer gaming and Internet gaming disorder. As we all know, heated debates have occurred on how society should deal with this new phenomenon. There is particular disagreement if computer gaming has to be generally perceived as a mere lifestyle that should not be problematized or if computer gaming can bear addictive potential for vulnerable individuals and be the cause of suffering (e.g., Aarseth et al., 2017; Billieux et al., 2017; Griffiths, Kuss, Lopez-Fernandez, \& Pontes, 2017; Király \& Demetrovics, 2017; Müller \& Wölfling, 2017). Thus, there could be a good match between the argumentation that playing computer games is not per se hazardous but rather a modern possibility of achieving certain skills and the concept of harm reduction. Yet, strategies specifically appropriate for harm reduction in problematic computer gaming have not yet been sufficiently developed or tested. The study by Király et al. (2018) enumerates three components and possibilities in that respect: (a) warning messages, especially appearing as part of the game itself; (b) rating games by "addictiveness" potential; and (c) reducing the addictive potential of some games.

The first proposal seems to be a feasible and ecological one and not surprisingly, which is already part of some computer games. Yet, the question remains whether such messages have any effect on the player's behavior or attitude toward the behavior. Data from experimental designs could shed light into this question but are not available at present.

The second aspect, introducing an addiction-specific rating for computer games is a promising one, yet, also a pie in the sky. As depicted by Király et al. (2018), similar attempts have been initiated in Hungary and Germany for gambling products. In Germany, this process was a long journey for many reasons. Discussing the possibilities of having such a rating system for computer games has recently been initiated in Germany but again the journey is going be a tedious one (Rumpf et al., 2017). Undoubtedly, having an addiction-sensitive rating system would be a great advantage. Research on exactly those elements that are responsible for causing an overcommitment to the player that, in the long run, might lead to loss of control, and Internet gaming disorder is an essential prerequisite for it. Although there are some empirical data on this topic available, we are currently far from having a clear picture of these elements. For instance, we know that certain reinforcement schedules and specific design factors (e.g., monetarization strategies; Dreier et al., 2017; King, Delfabbro, \& Griffiths, 2011) seem to play a crucial part in using the game. Yet, our in-depth knowledge on this matter is still limited. Again, more research is needed.

For the same reason, it is hard to estimate our possibilities of reducing the addictive potential of computer games, since this would require knowing more details on exactly these factors. In addition, the question remains if it may be exactly those factors enhancing the joy of gaming that may be on the same hand responsible for the addictive potential of the game. At present, we cannot give an answer to that question and the need for intensified research becomes evident again.

\section{SOME THOUGHTS ON THE NEXT STEPS}

Our experiences from substance-use disorders and gambling disorder taught that prevention is a complex matter demanding both financial expenses and sound scientific approaches to investigate its effectiveness. Methodologically, it is a great challenge to demonstrate if and how a certain prevention strategy works. Similarly, it is of high relevance to face the challenges of Internet gaming disorder not only by evaluating and implementing disorder-specific treatment programs but also by having effective and specific prevention and early intervention strategies. As it has been discussed before, it is reasonable to assume that it is the interaction between specific game features and characteristics of the player (e.g., individual risk factors) that is fostering problematic use and Internet gaming disorder. In order to identify individuals prone to the adverse effects of computer gaming, prospective studies are needed. Yet, in a recent systematic review of the existing literature, Mihara and Higuchi (2017) identified only 13 prospective surveys with sufficient methodological quality. A broader database would be extremely helpful for the purpose of selective prevention.

Similarly, we will have to take a serious look at the effects of harm-reduction strategies in the future. Trying to 
minimize hazardous effects caused by computer gaming seems to be a well-considered, even logical step in preventing Internet gaming disorder. Yet, we do not know if these efforts have noteworthy benefits in the long run. Again, prospective data are needed but missing.

\section{Funding sources: None.}

Author's contribution: KWM is responsible for draft, concept, and final version of the manuscript

Conflict of interest: The author declares no conflict of interest.

\section{REFERENCES}

Aarseth, E., Bean, A. M., Boonen, H., Colder Carras, M., Coulson, M., Das, D., Deleuze, J., Dunkels, E., Edman, J., Ferguson, C. J., Haagsma, M. C., Helmersson Bergmark, K., Hussain, Z., Jansz, J., Kardefelt-Winther, D., Kutner, L., Markey, P., Nielsen, R. K. L., Prause, N., Przybylski, A., Quandt, T., Schimmenti, A., Starcevic, V., Stutman, G., Van Looy, J., \& Van Rooij, A. J. (2017). Scholars' open debate paper on the World Health Organization ICD-11 Gaming Disorder proposal. Journal of Behavioral Addictions, 6(3), 267-270. doi:10.1556/2006.5.2016.088

Billieux, J., King, D. L., Higuchi, S., Achab, S., Bowden-Jones, H., Hao, W., Long, J., Lee, H. K., Potenza, M. N., Saunders, J. B., \& Poznyak, V. (2017). Functional impairment matters in the screening and diagnosis of gaming disorder. Commentary on: Scholars' open debate paper on the World Health Organization ICD-11 Gaming Disorder proposal (Aarseth et al.). Journal of Behavioral Addictions, 6(3), 285-289. doi:10.1556/2006.6. 2017.036

Cheung, L. M., \& Wong, W. S. (2011). The effects of insomnia and Internet addiction on depression in Hong Kong Chinese adolescents: An exploratory cross-sectional analysis. Journal of Sleep Research, 20(2), 311-317. doi:10.1111/j.1365-2869. 2010.00883.x

Dreier, M., Wölfling, K., Duven, E., Giralt, S., Beutel, M. E., \& Müller, K. W. (2017). Free-to-play: About addicted Whales, at risk Dolphins and healthy Minnows. Monetarization design and Internet gaming disorder. Addictive Behaviors, 64, 328-333. doi:10.1016/j.addbeh.2016.03.008

Ferguson, C. J., Coulson, M., \& Barnett, J. (2011). A meta-analysis of pathological gaming prevalence and comorbidity with mental health, academic and social problems. Journal of Psychiatric Research, 45(12), 1573-1578. doi:10.1016/j.jpsychires. 2011.09.005

Griffiths, M. D., Davies, M. N. O., \& Chappell, D. (2004). Demographic factors and playing variables in online computer gaming. CyberPsychology \& Behavior, 7(4), 479-487. doi:10.1089/cpb.2004.7.479

Griffiths, M. D., Kuss, D. J., Lopez-Fernandez, O., \& Pontes, H. M. (2017). Problematic gaming exists and is an example of disordered gaming. Commentary on: Scholars' open debate paper on the World Health Organization ICD-11 Gaming Disorder proposal (Aarseth et al.). Journal of Behavioral Addictions, 6(3), 296-301. doi:10.1556/2006.6.2017.037

King, D. L., Delfabbro, P. H., \& Griffiths, M. D. (2011). The role of structural characteristics in problematic video game play: An empirical study. International Journal of Mental Health and Addiction, 9(3), 320-333. doi:10.1007/s11469-010-9289-y

King, D. L., Delfabbro, P. H., Wu, A. M., Doh, Y. Y., Kuss, D. J., Pallesen, S., Mentzoni, R., Carragher, N., \& Sakuma, H. (2017). Treatment of Internet gaming disorder: An international systematic review and CONSORT evaluation. Clinical Psychology Review, 54, 123-133. doi:10.1016/j.cpr.2017.04.002

Király, O., \& Demetrovics, Z. (2017). Inclusion of Gaming Disorder in ICD has more advantages than disadvantages. Commentary on: Scholars' open debate paper on the World Health Organization ICD-11 Gaming Disorder proposal (Aarseth et al.). Journal of Behavioral Addictions, 6(3), 280-284. doi:10.1556/2006.6.2017.046

Király, O., Griffiths, M. D., King, D. L., Lee, H. K., Lee, S. Y., Bányai, F., Zsila, Á., Takacs, Z. K., \& Demetrovics, Z. (2017). Policy responses to problematic video game use: A systematic review of current measures and future possibilities. Journal of Behavioral Addictions, 7(3), 503-517. doi:10.1556/2006.6. 2017.050

Kuss, D. J., \& Griffiths, M. D. (2012). Internet and gaming addiction: A systematic literature review of neuroimaging studies. Brain Sciences, 2(3), 347-374. doi:10.3390/brainsci2030347

Lemola, S., Brand, S., Vogler, N., Perkinson-Gloor, N., Allemand, M., \& Grob, A. (2011). Habitual computer game playing at night is related to depressive symptoms. Personality and Individual Differences, 51(2), 117-122. doi:10.1016/j. paid.2011.03.024

Mihara, S., \& Higuchi, S. (2017). Cross-sectional and longitudinal epidemiological studies of Internet gaming disorder: A systematic review of the literature. Psychiatry and Clinical Neurosciences, 71(7), 425-444. doi:10.1111/pcn.12532

Müller, K. W., Beutel, M. E., \& Wölfling, K. (2014). A contribution to the clinical characterization of Internet addiction in a sample of treatment seekers: Validity of assessment, severity of psychopathology and type of co-morbidity. Comprehensive Psychiatry, 55(4), 770-777. doi:10.1016/j.comppsych.2014. 01.010

Müller, K. W., \& Wölfling, K. (2017). Both sides of the story: Addiction is not a pastime activity. Commentary on: Scholars' open debate paper on the World Health Organization ICD-11 Gaming Disorder proposal (Aarseth et al.). Journal of Behavioral Addictions, 6(2), 118-120. doi:10.1556/2006.6. 2017.038

Rumpf, H.-J., Batra, A., Bleckmann, P., Brand, M., Gohlke, A., Feindel, H., Perdekamp, M. G., Leménager, T., Kaess, M., Markowetz, A., Mößle, T., Montag, C., Müller, A., Müller, K., Pauly, A., Petersen, K.-U., Rehbein, F., Schnell, K., te Wildt, B., Thomasius, R., Wartberg, L., Wirtz, M., Wölfling, K., \& Wurst, F. M. (2017). Empfehlungen der Expertengruppe zur Prävention von Internetbezogenen Störungen [Recommendations of the expert group on the prevention of Internet-related disorders]. Sucht, 63(4), 217-225. doi:10.1024/0939-5911/ a000492 